\title{
An Assessment of College Students' Attitudes towards Using an Online E-textbook
}

\author{
Emilie O. Falc \\ Winona State University, Winona, Minnesota, USA \\ efalc@winona.edu
}

\begin{abstract}
In this digital age, e-textbooks are becoming more prevalent. This assessment surveys a group of public speaking students on their attitudes toward an e-textbook. A qualitative and quantitative approach to collecting student feedback using an online survey reveals mixed reviews of students' use of an e-textbook. In an introductory public speaking course, most of the respondents prefer using a combination of a print textbook with an e-textbook. Although many of the students surveyed experienced some frustrations and technical difficulty, most of the students found the etextbook to be helpful for assignments and studying for tests at least some of the time. Faculty could inform students of the drawbacks of e-textbooks and make suggestions on ways to maximize their effectiveness for better comprehension and less frustration.
\end{abstract}

Keywords: e-textbook, e-book, instructional technology, undergraduate students

\section{Introduction}

Many college students are facing high textbook costs in addition to rising tuition. With textbook prices adding to the stress on college students' budgets, professors and students seek ways to lower textbook costs. Some instructors use previous editions of texts so that used textbooks can still be purchased even when the publisher has released another new edition. Others make their own texts or skip using textbooks all together. Students now more commonly select e-textbooks as a way to reduce spending. Are e-textbooks a viable replacement for textbooks in undergraduate college-level classes? Are students readily adapting to the e-textbooks? How would students describe their experience with e-textbooks? Can professors confidently recommend e-textbooks to their students? This assessment indicates that the undergraduate students surveyed want to be able to freely choose between print and e-textbooks. While many students like using an e-textbook, faculty are encouraged to inform students of the benefits and limitations of e-textbooks.

Unlike most e-books such as novels, which are purchased and downloaded, e-textbooks have been primarily web-based books designed for use while online. (One e-textbook supplier has only recently made e-textbooks accessible offline when a student creates an Offline Bookshelf.) Students use laptops and other e-readers for reading their e-textbooks (Young, 2009). Some students

Material published as part of this publication, either on-line or in print, is copyrighted by the Informing Science Institute. Permission to make digital or paper copy of part or all of these works for personal or classroom use is granted without fee provided that the copies are not made or distributed for profit or commercial advantage AND that copies 1) bear this notice in full and 2) give the full citation on the first page. It is permissible to abstract these works so long as credit is given. To copy in all other cases or to republish or to post on a server or to redistribute to lists requires specific permission and payment of a fee. Contact Publisher@InformingScience.org to request redistribution permission. chose an e-textbook so they can buy a digital version of the text at a lower price than the print copy while also saving space in their book bags (Lyman, 2008). E-textbooks typically cost about half as much as a new print textbook, although e-textbooks cannot be sold back at the end of the course (Young, 2009). 
The publishers of textbooks clearly see some interest in e-textbooks. Publishers are now providing more e-textbooks, as digital replicas of the print versions, mainly through the CourseSmart Company (CourseSmart.com). CourseSmart was founded by and is supported by five higher education textbook publishers: Pearson, Cengage Learning, McGraw-Hill Education, John Wiley \& Sons Inc., and the Bedford, Freeman, Worth Publishing Group. CourseSmart provides an etextbook format on a common platform with a common location for reviewing and purchasing etextbooks (Lyman, 2008). In 2010, there were over 12,000 e-textbooks available, and now they offer over $90 \%$ of textbooks in use today (CourseSmart, 2013). Given the widespread availability of e-textbooks, this assessment can help faculty and students be prepared for a potential shift away from print textbooks to e-textbooks.

This assessment asks students in a public speaking course at a public university about their use of and opinions of an e-textbook, "A Speaker's Guidebook" (O’Hair, Stewart, \& Rubenstein, 2009) used in the introduction to public speaking course to understand student attitudes toward using an e-textbook. Faculty can benefit from knowing the attitudes undergraduate students shared in this survey towards the e-textbook so that they can better inform their own students about the benefits and pitfalls of e-textbooks. The next section will summarize previous research exploring the challenges of online reading and summaries of students' views on e-textbooks as reported in other surveys.

\section{Review of the Literature}

\section{Students' use of E-textbooks}

Buzzetto-More, Sweat-Guy, and Elobaid (2007) describe the digital media of e-textbooks as a learning object that includes features such as hyperlinks, multimedia features, and search ability, and they report that in 2007 many students had never used e-books. For those students who have used e-books, Li, Poe, Potter, Quigley, and Wilson (2011) report students' search tasks are quite efficient using e-books, and e-books are accessible virtually immediately online. E-textbooks can also make quick work of copying and pasting text for students (Li et al., 2011). These are benefits that support certain types of reading such as discovering new information or searching for terms or definitions. However, according to Young's (2009) survey of undergraduates at a public university using e-textbooks, $40 \%$ of those surveyed agree with the statement that they "study less because the e-textbook makes studying more difficult" while only $17 \%$ of undergraduate students report that an e-textbook helps them to "study more" (p. A18).

Previous research indicates that some students want to interact with the e-textbooks to mark their place and add notes. Simon's (2001) survey results indicate that about half of the students used bookmarking and highlighting functions available on an e-reader. The University of California Libraries report indicates that e-books were found to have disappointingly limited annotation tools, limited downloading, and limited printing (Li et al., 2011). While this might not seem to be a major flaw, there could be serious consequences for learning and writing.

\section{Student Attitudes of E-books and E-textbooks}

Reports from pilot studies at other universities and the e-book publishers indicate that many undergraduate students are interested in e-textbooks and some of their functions. Simon's (2001) pilot study of college students' use of an e-textbook (on a Rocket e-book reader) found that all 19 of the 19 students surveyed would recommend using an e-textbook to a friend. As for the benefits of e-textbooks, according to a survey by ePublisher CourseSmart, students report that they are looking for cost savings, searching utility, convenience, flexibility to copy/paste text into notes, and environmentally conscious printing of only select parts of the text (Lyman, 2008). Pei, Yan 
and Siew (2009) state that students are seeking easy-to-navigate e-textbooks with crossreferencing features and tools like bookmarking, highlighting, and annotating. Eric Frank, founder and president of Flat World Knowledge, a digital publishing company, says students tell them they are looking for efficiency. One student surveyed stated: "I'm not asking for someone to make my learning more engaging - I'm asking for them to make it more efficient" (as cited in Baumann, 2010, p. 44). McFall (2005) reports that students surveyed had generally neutral attitudes towards e-textbooks.

However, other pilot projects of students' use of e-textbooks show less favorable results. In their survey of undergraduate college students, Buzzetto-More et al.'s (2007) report indicates that "the vast majority of respondents lacked e-book experience and that the majority of students prefer traditional paper-based text" (p. 244). This indicates a prejudging of the digital media format and negative bias against e-books. Woody, Daniel, and Baker (2010) surveyed 91 undergraduate students about their use of an e-textbook in a psychology course, and the majority of students reported a preference for the print textbook over the e-textbook. Young (2009) reports that some of the 240 students who adopted e-textbooks in a pilot e-textbook program using Sony e-book readers had some difficulty using e-readers due to text layout differences between print and etextbook copies so they switched to using e-textbooks on laptops and computers. Even after the switch, Young states that almost $40 \%$ of students surveyed report that they study less because "the e-textbook makes studying more difficult" (p. A18). Young also reports that some students wish for more classroom time designated for how to use the e-textbooks, and others note that color graphs on a black and white e-reader appear unclear. Vernon (2006) reports that 58 of the 82 graduate students surveyed about their use of an e-textbook in a social work course were dissatisfied using the e-textbook due to concerns such as eyestrain and headaches.

While not specifically queried about e-textbooks, Li et al. (2011) report that a majority of the undergraduate students responding to a University of California Libraries survey regarding e-books stated that they preferred print books. The respondents in the University of California Libraries study with the highest preference for using e-books are postdoctoral researchers, graduate students, and faculty, especially when using the e-books for discovery and search tasks. Li et al. also report $58 \%$ of undergraduate students surveyed indicate a preference for print books while $27 \%$ preferred e-books. The survey report indicates that students had difficulty "learning, retaining, and concentrating while in front of a computer" (Li et al., 2011, p. 5). These attitudinal studies indicate that while some undergraduate students are willing and interested in adopting etextbooks or e-books for use in their coursework, it is rare to find overwhelmingly positive attitudes towards e-textbooks.

\section{Comparing the Outcomes of Using Print against Using Electronic Files}

Several recent studies point toward no significant difference in academic achievement in studies comparing print textbooks vs. digital or e-textbooks. Murray and Pérez (2011) found no significant difference in the test scores of undergraduate students enrolled in an online instructional technology course for those using a print textbook and those using an e-textbook. McFall (2005) found no significant difference in student learning comparing undergraduate students using an etextbook and those using a print textbook. Shepperd, Grace, and Koch (2008) found no significant difference in the course grade of students enrolled in a psychology class for those using a print textbook and those using a digital textbook (provided on a $\mathrm{CD}$ ), although the mean grade was slightly higher for those using a print textbook.

However, new research shows that students' learning could suffer due to e-textbooks format hindering reading comprehension. A recent long-term study by Thayer et al. (2011) of reading an ebook using an e-reading device (Kindle Dx) involving graduate students concludes that the stu- 
dents are hindered by limitations in their ability to annotate and to "construct cognitive maps of texts" during active reading, where, for instance, students are interacting with the texts to take notes (p. 2918; for a discussion on the theory of active reading see Pugh, 1979). Thayer et al. rely on Waller's (1986) description of cognitive mapping: "many readers can remember or find ideas by their location on the page" (p. 72). Waller articulates a concern that e-books might make it harder for readers to "retrace their path or locate ideas which at first seemed irrelevant but now need more attention" (p. 73). Thayer et al. confirm Waller's hypothesis in their research stating that students reading e-books miss landmarks, such as headings and illustrations, that typically help readers map out the ideas.

Additional research studies on using digital texts on computers call to our attention limitations related to reading and writing in digital documents. The need to both read a digital document and create a digital document is common when using e-textbooks for assignments such as writing outlines, bibliographies, and reflection papers. O'Hara and Sellen's (1997) study compares using paper for reading and writing to using Microsoft Word 6.0 digital files for reading and writing. Respondents reading the digital files and composing a summary in Word state that it is harder to make annotations that appear as one's own and to view a whole page or three documents at once in order to integrate their reading and writing. Manipulating the digital documents is distracting. On the other hand, manipulating paper sheets for the other respondents is automatic and flexible, allowing files to be shuffled into piles, overlapping, or at angles to each other easily. Sellen and Harper's (2002) ethnographic study of the International Monetary Fund (IMF) offices in D.C. finds similar limitations in using digital files in which results show that IMF economists prefer to use paper documents, not digital documents on laptops, for reviewing and revising and for leading discussions. One IMF employee notes manipulating digital documents requires scrolling to the right spot and then "more fiddling" when making modifications (Sellen \& Harper, 2002, p. 67). Sellen and Harper conclude that paper "supports reading" in the following ways:

1. Paper helps us flexibly navigate through documents.

2. Paper facilitates the cross-referencing of more than one document at a time.

3. Paper allows us to annotate documents easily.

4. Paper allows the interweaving of reading and writing (p. 76).

These studies indicate that the ease of using paper for reading and writing tasks is not matched by using digital texts, even though they have some of their own previously stated unique benefits. While the two examples of studies of digital texts focus on workplace and not educational use of digital documents, they can still inform our understanding of the benefits of print textbooks. This study is particularly relevant to students whose reading and learning is supporting the activity of writing, e.g., writing outlines and essays in communication and other liberal arts courses. Furthermore, this is one of the few qualitative studies comparing print to digital media.

Interestingly, Sellen and Harper (2002) predicted greater use of home printers to print digital texts. One reason for this is that the cost of shipping is greatly reduced or eliminated in using digital documents. Another reason is that one can print selected pages of the chapters assigned and not need to print unassigned chapters. Thus, even though this approach consumes natural resources and adds an additional cost, a student could employ a conscientious approach by printing double-sided pages.

In sum, while there is evidence of student interest in e-textbooks and a quickly growing collection of e-textbooks, the research indicates some limitations for reading comprehension and combined reading and writing activities. Further research on the effects of reading comprehension are needed but not within the scope of this project. One might in the future investigate how students will adapt to this digital mode. 


\section{Research Goals and Questions}

The purpose of this study is to assess student use and attitudes of e-textbooks in a first-year student course at a laptop university and to query if students and professors should have easy access to both print textbooks and e-textbooks. This study asks if the undergraduate college students in an introductory communication course will have generally positive or negative attitudes about using e-textbooks for assignments and for studying. This study provides quantitative and qualitative feedback in the students' own words that more richly describes their experiences than with quantitative feedback alone.

Q1: How many times per week did the students use the e-textbook?

Q2: How many times per week did the students experience difficulties using the e-textbook?

Q3: What are students' attitudes towards using an e-textbook in an introductory public speaking course?

\section{Method}

\section{Participants}

Participants in the survey were undergraduate students at a mid-sized state university. This university participates in a laptop program so that all full-time students pay a fee each semester to lease a laptop from the university. Therefore, the participants all had access to a laptop. Students in two sections of a required introductory-level Public Speaking course were given an opportunity to respond to an online survey available to them through their online course support. Of the 45 students invited, 34 students $(75 \%)$ responded.

\section{Procedure}

At the beginning of the semester, students received an e-mail explaining that the e-textbook was required reading and that printed textbooks were also available at the university bookstore. All of the full-time students lease laptops through this university, and thus e-book readers were not necessary for this project. All of the classrooms are Wi-Fi equipped. An online questionnaire using an online course support tool was developed to survey use and attitudes using likert-scale response-type and true/false-type questions for close-ended questions and several open-ended questions to provide both quantitative and qualitative data. The questions asked students about their use of the e-textbook and its supplemental resources regarding their preferences, its helpfulness, technical problems and cost (see Appendix for survey instrument). Responses were analyzed for themes.

The course instructor e-mailed students an invitation to take the survey and students were allowed two weeks to respond. Students were reminded in class and via e-mail to respond to the survey during the two weeks.

\section{Results}

The results from the survey were analyzed for descriptive data from the open-ended questions. The results of the survey indicate that $94 \%$ of the students surveyed were using the e-textbook regularly. Fifty-nine percent of students reported that they used the e-textbook 1-2 times a week. Thirty-five percent indicated that they used it 3-5 times, and only 6\% said that they didn't use it. Of those students using the e-textbook, 38\% reported having trouble accessing it 1-2 times per week and 9\% report having trouble 3-5 times per week (see Table 1). 
Table 1: Student difficulties accessing an e-textbook

\begin{tabular}{ccc}
\multicolumn{2}{c}{ Difficulties Accessing E-textbook Chapters, Website, Videos, and/or Quizzes } \\
\hline Times/Week & Responses & $\%$ \\
\hline 0 & 18 & $52.94 \%$ \\
$1-2$ & 13 & $38.24 \%$ \\
$6-5$ & 3 & $8.82 \%$ \\
$6+$ & 0 & $0 \%$
\end{tabular}

Student attitudes were reported as favorable more often than not (see Figure 1). Even though many students (47\%) reported trouble accessing the e-textbook website, a chapter, video, and/or quiz in the e-textbook, $80 \%$ reported that the e-textbook was helpful for working on assignments or preparing for a test, and $79 \%$ liked not having to carry around another book. Of the students surveyed, $47 \%$ indicated that they "enjoy" using the e-textbook, and $88 \%$ found the information in it to be clear and helpful. In addition to these descriptive statistics, several themes emerged in the students' written responses ranging from technical difficulties accessing the e-textbook to ease of use.

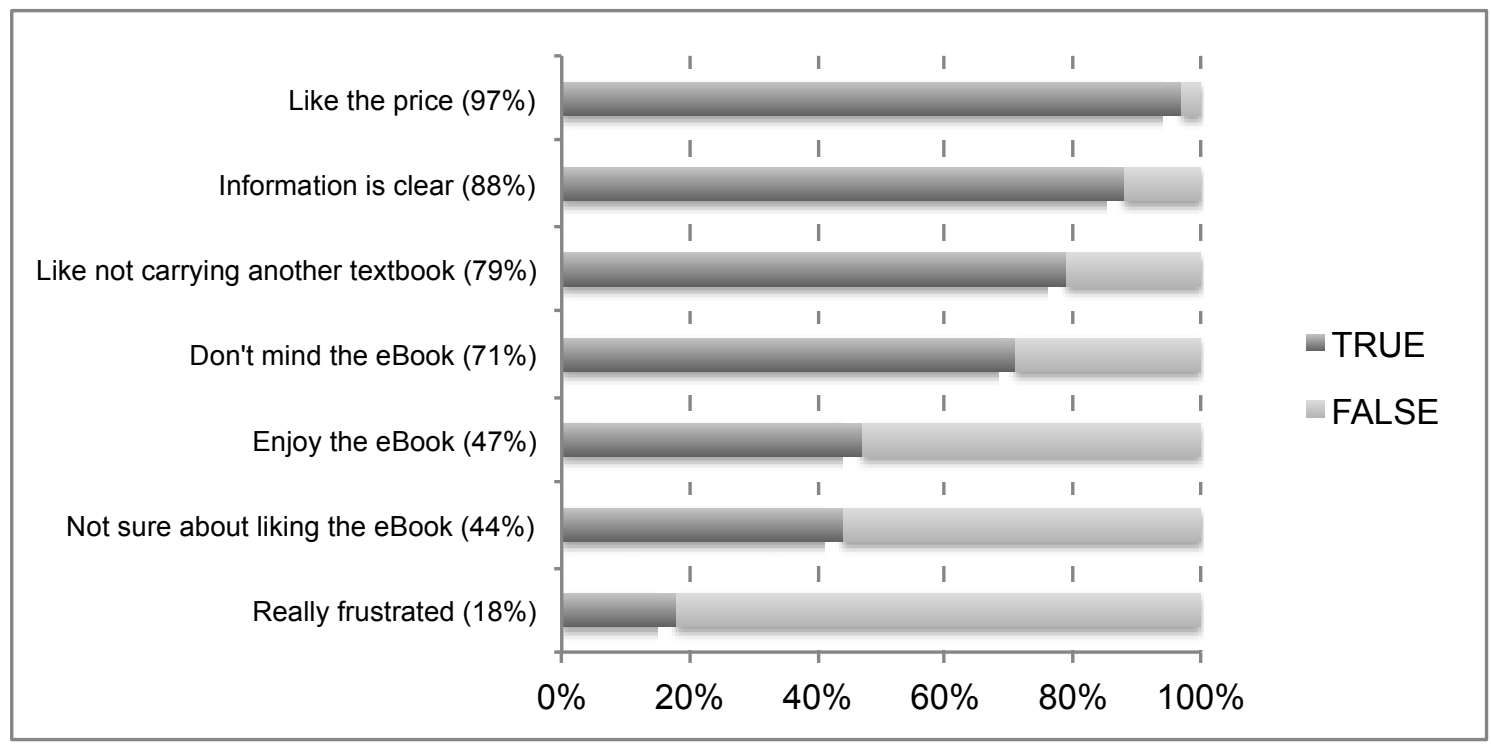

Figure 1: Student attitudes toward an e-textbook

One theme emerging in the responses indicates initial set-up difficulties as well as frequent difficulties with usability. Students had technical difficulties using the e-textbook both in class and outside of class time. These included temporarily not being able to access the Internet, the publisher restricting access by blocking the user if they attempted to login while it was already open in another window, trouble accessing the quizzes, and mistakenly clicking on the chapter quiz links when trying to access the e-textbook chapters. Some students indicated initial frustrations such as having a problem with their password and difficulty entering the website. Four students complained of trouble when Internet access is not available or when the server is down. One student wrote that "The Internet isn't always working, and when we have to study for a test coming up and you cannot access the book it's impossible to study." While on-campus Internet connectivity tends to be fairly reliable; outages do happen and it caused added test anxiety for this user to experience a connectivity problem since the e-textbook was only available online. 
Several students attributed problems to "Company rules" that make it harder to read the etextbook indicating that the "lock out feature" causes trouble when you "try to get back in too early and it locks you out even longer." This feature seems to limit access to the e-textbook to only one active browser window at a time, and so if you already have it open and try to open it in another window, you are "locked out" for a time. Some students said it was" slow to load" or "does not load," and therefore become distracted easily by the Internet. Problems such as these reduce the ease and efficiency that students want in an e-textbook.

Overall attitudes regarding pricing and features of this e-textbook are generally positive. A strong majority of the students surveyed (62\%) report paying for their own textbooks, and $97 \%$ said they like the lower price of the e-textbook compared to the print version. One student noted that he or she was somewhat disappointed that he or she could not resell the e-textbook. Many of the students like the ease of using an e-textbook and not carrying a physical textbook. Other comments included that it was easy to use, easy to search, easy to use multiple tabs, had fast loading pages, and "you never forget to bring your book." Students also noted that the book seemed informative, offering good details, good examples, and help when writing outlines. One student specifically noted that the hyperlinked terms offer dictionary definitions.

The students were not, however, completely satisfied with the layout and format of the etextbook. They had some frustrations with the format and interacting with it. Four students indicated that they found it harder to read on the screen. One wrote, "I'd rather use a paper book even if it is more money." Reading for a long time on the screen was discussed as problematic. Also, it was harder for a student to take notes while reading the e-textbook. These issues could be significant due to difficulty with concept mapping (as researched by Thayer et al., 2011) and not utilizing the annotation features.

Some students did not like the poorly worded quizzes and others had some difficulty locating information. A few indicated they found it not as reliable as a print textbook. One student wrote, "I despise it. I would much rather use a print copy. My eBook always seems to have some problem with me." This student personifies the eBook and considers his or her relationship to be one of conflict and strong negative emotions. Another student reported diminished efficiency because there are "too many distractions online." In today's digital age, students are navigating among a myriad of digital media competing for their attention. Another student indicated that he or she liked nothing about it, and "Print books are the best." This student clearly identifies as a print media user and is less likely than others to accept e-textbooks. One student, who seems to recognize the wave of digital media is coming and he or she is behind the curve, wrote: "I still like reading paper copies." While most students were willing, on the whole, to use the e-textbook and appreciated some of its offerings, a theme emerged in the student responses around the preference for a print textbook's layout and convenience.

Students were thoughtful about how the publisher could improve the e-textbook for future students. Some student suggestions for improving the e-textbook included making the glossary available by chapter and providing mini quizzes at the end of a reading.

With this e-textbook, the publisher included a speech-outlining tool and chapter quizzes, and a video library provided supporting materials. All of the students were required to take the online quizzes provided by the publisher. Some of the students indicated that they were aware of and used the supporting materials such as the Bedford Speech Outliner. Several students liked using the speech-outlining tool since it was easy to follow the guidelines, even when technical difficulties occurred. Three students liked having access to the chapter quizzes and several preferred the online and open-book quizzes rather than a traditional closed-book, in-class quiz format. Three students reported referring back to the quizzes to study for the tests. Three students reported using 
the online video library to help prepare for speeches. Having these additional resources could be an excellent reason for publishers to bundle the e-textbook along with the print book.

\section{Discussion}

Students are willing to use an e-textbook to access knowledge and tools for their success on course assignments and tests. In spite of some drawbacks and dissatisfaction, most of the students surveyed "don't mind using the eBook" and almost half the students surveyed reported that they enjoy it. This is consistent with previous attitudinal surveys. Some students in this survey expressed similar concerns found in other surveys such as some problems with the layout and readability (Thayer et al., 2011; Vernon, 2006; Young, 2009). Furthermore, 18\% of students surveyed were really frustrated with the e-textbook. The students who are frustrated with the e-textbook have some valid concerns as they navigate online e-textbook. Some students become easily distracted by other online activities. Some students were not able to study for test due to access problems and technical difficulties. If e-textbooks are intended to be more efficient, in those specific cases they do not meet that mark.

\section{Limitations}

A limitation of this survey is that this study was designed within an online course support tool to provide a view of students' attitudes that is not sortable by gender, ethnicity, age, or other demographics. This is also a small pool of 34 students--although this general education requirement attracts students of varied majors and minors.

\section{Implications}

This survey indicates that while students prefer having a choice of a print textbook, e-textbook, or using both mediums, they also need to know more fully the benefits and limitations of etextbooks. While some of the students' frustration could be due to the particular publisher and platform, faculty should use caution when adopting an e-textbook for their course. Faculty should communicate some of the limitations of e-textbooks, especially concerns that frustrations with etextbooks could decrease studying time, challenge note-takers, and add a layer of distraction. If students use the e-textbook, professors should inform them on how to annotate and bookmark the digital files and also encourage students to print the assigned chapters of the e-textbook (if available).

Faculty might also be frustrated with communicating that an e-textbook is required reading. One hurdle for the ordering of textbooks was that our bookstore's online ordering system does not provide the instructor an easy way to indicate to students that they could order the e-textbook, the print book, or both. Thus, bookstore managers should be aware that many students enjoy using etextbooks, but many still want the reliability and layout of print textbooks. In addition, publishers might provide more bundling of print and e-textbooks so that students have access to the multimedia features.

In the future, a survey on e-textbooks should separate out more carefully questions regarding students' use of the e-textbook for completing assignments from using e-textbooks for studying for tests, since studying a text and using it as a resource are two clearly different functions. The survey should also sort out which students were exclusively using the e-textbook as compared to those who had both the print textbook and the e-textbook. The survey could also assess students' attitudes towards the instructor's use of e-textbook pages and the publisher's sample speech videos during class discussions. Perhaps having access to some of these materials after class via the e-textbook could help students reinforce the concepts. The survey should also ask specifically about each of the tools the publisher provided (such as the outliner tool for assisting in writing a 
presentation outline) to find out how many students used those tools on their own. Survey questions should also ask specifically about attitudes towards using e-textbooks as guidebooks for their written assignments. A future survey could also ask students about how they use a tablet, such as an iPad, in conjunction with their laptop while they are reading their e-textbook or working on written assignments and using their e-textbook as a guide.

As many universities adopt environmental impact policies, it would be interesting to assess student's perceptions of e-textbooks as a more environmentally sensitive choice. One could also inquire on the uses of e-textbooks if the online format with online dictionaries easily accessed might be particularly useful for international students who are negotiating English as a second language. Lastly, future assessments should make comparisons across different groups in their attitudes towards the e-textbooks, such as comparing traditional with non-traditional students or comparing American students with International and ELL (English Language Learner) students to explore how those learners interact with online e-textbooks.

There are several possible directions for the future of e-textbooks. Cliff Rotenberg (from Elsiever publishing) says, "What we foresee is a blended sort of model in the foreseeable future, where there is going to be a set of online services and print textbooks" (as cited in Baumann, 2010, p. 48). Mohammed (2010) suggests that publishers offer print and e-books bundled together at a discounted price so that readers can use the e-book in public and the print book at home (p. 52). However, CourseSmart is now offering the option to print up to 10 of pages of a textbook at a time and a personal "Offline Bookshelf" for easier access when unable to connect to a network (CourseSmart, 2013). Publishers are also now formatting e-textbooks for eBook readers. The newer eBook readers such as the Kindle might cause less eye-strain because they use electronic ink instead of LCD screens, and the new Kindle Fire (along with the iPad and Android tablet) provide a color screen to make those graphs and charts more easy to read. CourseSmart also provides apps to access e-textbooks on other mobile devices; however, the smaller screens seem less likely to be the popular viewing method for most tasks except for a quick search or skimming.

Writers of textbooks could consider making their e-textbook chapters more interactive. While instructors traditionally quiz students by chapters or units, mini quizzes within the chapters could make better use of the dynamic online format by engaging students in more active learning.

While students are looking for efficiency and ease of use, faculty and publishers should be aware that some students are not (yet) willing to give up the security of having a print copy of the textbook (Vernon, 2006; Woody et al., 2010). Students might need to develop a different style of studying e-textbook information that is more interactive (such as reading smaller sections of a chapter and having a mini quiz) and not attempting to read several chapters on a small screen in a long stretch. Given the research results from Thayer et al. (2011) that show a decrease in reading comprehension along with students' reported frustrations with interacting with the online format reported in these survey results, faculty should encourage students to consider printing out chapters of the e-textbook to better support their learning. As mentioned above, CourseSmart is now allowing students to print 10 pages at a time of e-textbooks. Alternatively, perhaps printable summaries of sections of the full text might be useful.

\section{Conclusions}

We can anticipate that publishers will continue to make changes to e-textbooks. The insights from this survey should help shape those changes for the benefit of students' learning. Sellen and Harper (2002) conclude, "In the short term, new technologies will usually shift the role of paper, rather than replace it. Because change is an evolutionary process in complex environments, the new will not replace the old but will coexist with it" (p. 194). Perhaps the option to print chapters of etextbooks, as needed, will bridge the gap between the new and old technologies. 
While this assessment of public speaking students shows some openness in students' attitudes towards e-textbooks, it reinforces the notion that students want to have choices available to them that fit their needs and preferences. Students also need the flexibility of printing digital documents for their ease of use and making mental maps of the text. Faculty can discuss the positives and negatives of each textbook format including the possible technical difficulties that can occur on the first day of class so students can decide for themselves as more informed consumers and prepare for success.

\section{References}

Baumann, M. (2010). Ebooks: A new school of thought (Cover story). Information Today, 27(5), 1-48.

Buzzetto-More, N., Sweat-Guy, R., \& Elobaid, M. (2007). Reading in a digital age: E-books are students ready for this learning object? Interdisciplinary Journal of Knowledge and Learning Objects, 3, 239250. Retrieved from http://www.ijello.org/Volume3/IJKLOv3p239-250Buzzetto.pdf

CourseSmart. (2013). Retrieved from http://www.coursesmart.com

Li, C., Poe, F., Potter, M., Quigley, B., \& Wilson, J. (2011). UC Libraries academic e-book usage survey. University of California, Springer e-Book Pilot Project, Reader Assessment Subcommittee. Retrieved from http://www.cdlib.org/services/uxdesign/docs/2011/academic ebook usage survey.pdf

Lyman, F. (2008). Students enjoy lower costs, lighter backpacks as e-textbook availability expands dramatically. Community College Week, 8.

McFall, R. (2005). Electronic textbooks that transform how textbooks are used. The Electronic Library, 23(1), 72-81. doi: 10.1108/02640470510582754

Mohammed, R. (2010). How about 'both' instead of 'either/or'? Publishers Weekly, 257(22), 52.

Murray, M. C. \& Pérez, J. (2011). E-textbooks are coming: Are we ready? Issues in Informing Science and Information Technology, 8, 49-60. Retrieved from http://iisit.org/Vol8/IISITv8p049060Murray307.pdf

O'Hair, D., Stewart, R., \& Rubenstein, H. (2009). A speaker's guidebook to public speaking e-book (4th ed.). Bedford/St. Martin's Press.

O'Hara, K., \& Sellen, A. (1997, March). A comparison of reading paper and on-line documents. Proceedings of the SIGCHI Conference on Human Factors in Computing Systems, ACM Press, 335-342. doi:10.1145/258549.258787

Pei, F. C., Yan, P. L., \& Siew, W. L. (2009). On the design preferences for eBooks. IETE Technical Review, 26(3), 213-222. doi: 10.4103/0256-4602.50706

Pugh, A. K. (1979). Styles and strategies in adult silent reading. In P. A., Kolers, M. E. Wrolstad, \& H. Bouma (Eds.), Processing of visible language (pp. 171-186). New York: Plenum Press.

Sellen, A., \& Harper, R. (2002). The myth of the paperless office. Cambridge, MA: Massachusetts Institute of Technology Press.

Shepperd, J. A., Grace, J. L., \& Koch, E. J. (2008). Evaluating the electronic textbook: Is it time to dispense with the paper text? Teaching of Psychology, 35, 2-5. doi: 10.1080/00986280701818532

Simon, E. J. (2001, Winter). Electronic textbooks: A pilot study of student e-reading habits. Future of Print Media Journal, Institute for Cyber-Information, Kent State University. Retrieved from http://www.ericjsimon.com/papers/papers/ebook.pdf.

Thayer, A., Lee, C. P., Hwang, L. H., Sales, H., Sen, P. \& Dalal, N. (2011). The imposition and superimposition of digital reading technology: The academic potential of e-readers. Proceedings of the SIGCHI Conference on Human Factors in Computing Systems, ACM Press, 2917-2926. doi:

$10.1145 / 1978942.1979375$ 
Vernon, R. F. (2006). Paper or pixels? An inquiry into how students adapt to online textbooks. Journal of Social Work Education, 42(2), 417-428. doi: 10.5175/JSWE.2006.200404104

Waller, R. (1986). What electronic books will have to be better than. Information Design Journal, 5(1), $72-$ 75.

Woody, W. D., Daniel, D. B., \& Baker, C. A. (2010). E-books or textbooks: Students prefer textbooks. Computers \& Education, 55, 945-948. doi: 10.1016/j.compedu.2010.04.005

Young, J. (2009). 6 lessons one campus learned about e-textbooks. The Chronicle of Higher Education, 55(39), A18.

\section{Appendix E-book Survey Instrument (2010)}

1. How often do you use the e-book, A Speaker's Guidebook (O'Hair, Stewart \& Rubenstein, 2009), per week?

0

$1-2$

3-5

$6+$

2. How often do you have trouble accessing the e-book website or a chapter or video or quiz within the website per week?

0

$1-2$

3-5

$6+$

3. If you had the choice and price was no concern, which would you prefer?

E-book

E-book and print copy of the book

Just the Print Copy

Neither

4. How often do you find the e-book and its resources to be helpful when working on assignments for the class or preparing for a test?

All the time

Sometimes

Rarely

Never

\section{Indicate True or False for the following statements}

5. I don't mind using the e-book.

6. I pay for my own textbooks instead of having parents or others pay for them.

7. I like not having to carry around another book.

8. I like to use e-books but not for this class.

9. I've never had to use an e-book before this class.

10. I am really frustrated with our e-book.

11. I'm not sure if I like the e-book or not.

12. I like that the e-book is about half the price of the print book.

13. I enjoy using the e-book. 
14. When I am reading a chapter, the e-book provides clear instructions and information about public speaking.

\section{Open-ended questions}

15. What problems or concerns do you have with the e-book?

16. What do you like about the e-book and the related supporting materials such as the Speech outliner and online Video Library?

\section{Biography}

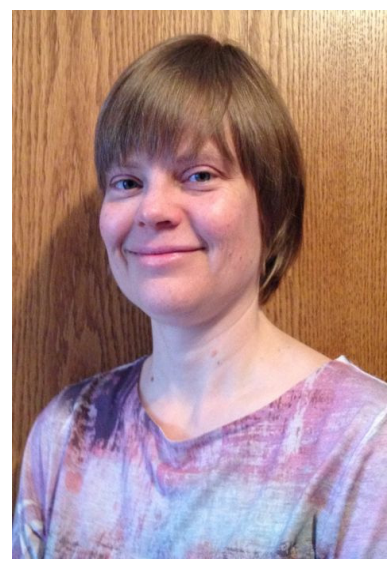

Dr. Emilie Falc is an Assistant Professor in the Communication Studies Department at Winona State University in Winona, Minnesota. She holds a Ph.D. from the school of Interpersonal Communication at Ohio University. Her research interests include instructional technology and rhetorical criticism of feminist rhetoric and environmental communication. She drafted this paper on a MacBook Pro laptop in a boathouse on the Mississippi River. She is grateful for the help and suggestions from Nick Carr, Joan Francioni, Kirsten Uhlenberg, and the reviewers and editors of IJELLO in the process of revising this paper for publication. 